\title{
Making Projects Real in a Higher Education Context
}

\author{
Roy Hanney
}

\section{Introduction}

A reconceptualisation of projects, away from projects as a model of management towards projects as a model of practice (Hodgson \& Cicmil, 2006), offers an opportunity to see project-based learning $(\mathrm{PjBL})$ as a social practice (Fig. 8.1). Given the desirability of the use of live projects as a means of drawing real world learning into the curriculum, this approach offers a new perspective that begins to address a number of problems with project working within a higher education context. It takes as a founding principle the notion that real world learning occurs within a community of practice (Wenger, 1998) and argues that, for real world learning to occur, educators within HEI's need to foster communities of practice (Wenger, 1998) within which students can participate as productive members.

Case studies: Rhiannon Jones, Ana Gaio and Lada T. Price

R. Hanney $(\bowtie)$

Solent University, Southampton, UK

e-mail: roy.hanney@solent.ac.uk 

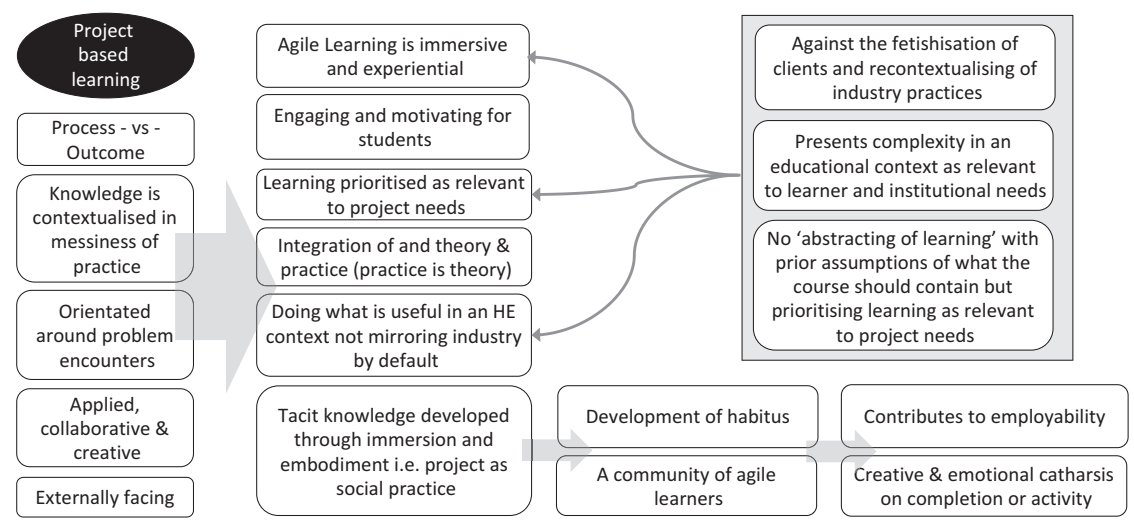

Fig. 8.1 Agile learning through PjBL concept map

A community of practice (Wenger, 1998) requires novices to learn more than just technical competences and entry level practical skills. They are socialised into a community of practice through the experience of socially situated signifying practices. Students are therefore exposed not only to what can be seen to be done but also to that which is hidden through tacit understanding, transmission of meaning, contextualisation of tools and techniques, all of which render the experience more meaningful. The chapter addresses how we as educators build into the learning process the kind of experience that enables students, as novice practitioners, develop the kind of tacit sensibilities found among expert practitioners.

A shift from executability to learnability of projects foregrounds the ontological characteristics of a 'becoming mode' of project working (Hanney, 2018). It is one that offers opportunities for exploring the ways in which educators can transition communities of learners into communities of practice and thereby lead to a process of socialisation into real world working. Case studies drawn from examples of project-based learning on a range of practice-based course at UK HEI's will illustrate how such a reconceptualisation of projects (Bredillet, 2010) might aid educators in making projects real in an HE context. 


\section{Rethinking Project Management}

Many of the classical texts on project management begin with the assumption that projects are a historical phenomenon, citing examples such as the pyramids (cf. Nicholas, 2004; Shenhar \& Dvir, 2007), the Great Wall of China, the Tower of Babel, or even the act of Creation itself (cf. Morris, 1994) as evidence of the historicity of this concept. There is though, no historical evidence to support such claims and it is unlikely that these ancient peoples employed the kinds of models of organisational control that would today be recognised as project management. In fact, the term is believed to have first originated in an article in the Harvard Business Review in 1959 (Winter, Smith, Cooke-Davies, \& Cicmil, 2006) reflecting a then emerging sub-discipline of organisational studies which concerned itself with the adoption of newly formulated tools for the optimisation of organisational process (Bredillet, 2010). The classical view of a project as a temporary endeavour undertaken to create a unique product, service or result (Project Management Institute) is further codified through the development of professional bodies and institutionalised frameworks during the 1960s. During this period, we also see the arrival of large-scale project methodologies such as the Project Management Body of Knowledge which is developed by the Association of Project Managers, along with Projects in a Controlled Environment 2 which is developed by the UK government. The main focus of these approaches was to provide a normative framework for managing task-orientated activities within a directed command and control hierarchy (Winter et al., 2006) for delivering organisational benefit. A project is formulated by these systems approaches as an instrumental tool for managing project process and the metaphor for this methodology is that of a "machine that requires optimisation" (Svejvig \& Andersen, 2015, p. 280), the main focus for which is the execution of a task.

Around the turn of the millennium, a number of researchers in the field of project studies began to re-evaluate the way in which projects were conceptualised in order to "better account for project phenomena" (Floricel, Bonneau, Aubry, \& Sergi, 2014, p. 1091). By redirecting their accounts away from the instrumental towards the social, they aimed to 
develop a deeper understanding of the nature of projects and project organisations. This became known as the Scandinavian School within the literature on the subject (cf. Lundin \& Söderholm, 1995; Packendorff, 1995; Sahlin-Andersson \& Söderholm, 2002). Instead of orientating themselves towards a positivist or functionalist conception of projects aimed at the optimisation of performance, they begin to present projects as a "lived experience" (Floricel et al., 2014, p. 1094). Thus, scholars in the field begin to reflect on the lived reality of what it is to do projects leading to a recognition of a project as a temporary organisation established by its base organisation to carry out an assignment on its behalf (Packendorff, 1995), the main focus for which is value creation, that is, to create a desirable development in another organisation (Winter et al., 2006). Table 8.1 sets out some key contrasts between the two views of a project. Of interest here, given the context of the study, is the shift away from executability towards learnability as a philosophical framework: a key distinction that informed the theoretical perspective of the research undertaken into project-based learning.

This is important because it begins to offer a way of thinking about how the siting or location of a project (i.e. in industry or in education) might impact on the use of projects. Particularly, in a pedagogic context, it might be beneficial to think about the nature of projects as a concept. However, while the rethinking projects view "reflects a broader and more holistic perspective in which projects might be conceptualised as temporary organisations" (Svejvig \& Andersen, 2015, p. 280). It is important to recognise that this new concept builds in a pluralistic way on what has gone before and sees the classical tradition as embedded within the rethinking approach. That is to say, while there are of course benefits to those doing projects in the adoption of the instruments, tools and

Table 8.1 Contrasting views of a project adapted from Svejvig and Andersen (2015, p. 280)

\begin{tabular}{lcc}
\hline Classical project management & -vs- & Rethinking project management \\
\hline Executability, simplicity, & & Learnability, multiplicity, \\
temporarity, linearity, & temporarity, non-linearity, \\
controllability and & complexity, uncertainty and \\
instrumentality. & sociability. \\
\hline
\end{tabular}


concepts drawn from the classical approach, to do so uncritically renders only a partial theorising of what it is to do a project (Hodgson \& Cicmil, 2006).

\section{The Critical Projects Movement}

The launch of an ongoing series of symposiums entitled Making Projects Critical in 2003 heralds the arrival of a platform for divergent critical perspectives that offer alternative viewpoints on projects. The symposium led to the publication of a key text in the literature and, in 2009, to the publication of a special issue of Ephemera (Cicmil, Hodgson, Lindgren, \& Packendorff, 2009), further developing this school of socio-political critique and the re-imagining of projects. Thus, the Critical Projects Movement emerged as a response to the need to draw upon ever more interdisciplinary resources in order to counter what is conceived as the techno-rationalism of the positivist view of projects (Cicmil et al., 2009). The movement critiques traditional assumptions made about project methods including the idea that they are "compelling and essentially sound" (Hodgson \& Cicmil, 2008, p. 145), suggesting instead that there is an increasing body of evidence to suggest that these are anything but sound. They argue that the focus on tools and techniques doesn't allow for a critique of politics, power and the historically embedded nature of projects (Cicmil et al., 2009).

Instead the Critical Projects Movement sets a new agenda that draws upon a "wider and more critical intellectual resources than the instrumental rationality, quantitative and positivist methodologies and technicist solutions which have been traditionally brought to bear in attempts to understand and control the project form of organising" (Cicmil et al., 2009, p. 86). For example, Winter et al. (2006) questions a dominant assumption in project management studies that the model of project life cycle should be the primary object of study. Such an assumption results in an emphasis on the creation of a product rather than creation of value (Winter et al., 2006) and the benefit of a project to the different groups of project stakeholders (including the participants). This shifting of attention away from product to value is of key interest for educators since, it 
is argued, in project-based learning, the final output (i.e. product) is a consequence of the doing (i.e. value) of a project. In other words: it is the experience of doing a project not the final artefact that drives learning. Winter et al. (2006) goes on to argue that our theories are only ever partial, and that the complexity of a project is such that often our models and theories fail to acknowledge this. It is the acknowledgement of this complexity and the need to theorise it adequately that has led to the rethinking and reconceptualising of projects presented here.

\section{Projects as Practice}

This re-imagining of projects as a lived experience gives primacy to an interpretivist or relativist ontological account (Lewis, 2013, p. 14) of projects over those with a concern for codified, normative models of management. The rejection of what might be thought of as an empirical realist ontology (Lewis, 2013, p. 14) allows for the investigation to recognise the situated nature of projects as a form of social practice that is subject to continual change. Following Linehan and Kavanagh (2006, p. 55) it might be possible to begin to think of a project as an emergent or "becoming ontology". A becoming ontology embraces the Heraclitean notion of the world as chaotic and ever unfolding and stands in contrast to a Parmenidean, being ontology, which embodies instrumental, regulatory principles for structuring experience (cf. Hanney, 2018, p. 11). Again, a differentiation is posited between the metaphorisation of a project as a machine to a project as a practice (Gauthier \& Ika, 2012, p. 15), in other words, a shift between models of organisation and models of practice. What is seen here is that the Critical Projects Movement challenges our understanding of projects and project management by highlighting alternative perspectives. Linehan and Kavanagh argue that rather than take a singular point of view about projects it is "better to think of a project first as a language and second as a practice" (Linehan \& Kavanagh, 2006, p. 55). Thus, the shift from a realist to a relativist ontological account of projects mirrors the "practice turn" in sociology (Blomquist, Hällgren, Nilsson, \& Söderholm, 2010, p. 9) and offers a view of projects as a 
socially constructed enterprise that places human agency at the heart of any meaningful enquiry into the subject.

It is argued that the relationship between structure and agency is a dialectical one and both Giddens (1984) and Bourdieu (1988) identify the mutually constitutive relationship between structure and agency (Seo \& Creed, 2002), suggesting that tensions between structural elements within social relations (contradictions) have the effect of empowering social actors to become "change agents" (Seo \& Creed, 2002, p. 223). In fact, Bloomquist goes further (Blomquist et al., 2010, p. 7) and, following Bourdieu (1990), argues the relationship between structure and agency is a causal one. For these scholars, agency is understood as a form of praxis or, in other words, as any "action embedded in a historical system" (Seo \& Creed, 2002, p. 223) that comes about as a result of the "ruptures and inconsistencies within social relations" (Seo \& Creed, 2002, p. 225) and enables social actors to engage in a restructuring of social relations within which they are embedded. For Bourdieu (1984) an investigation of praxis includes a study of what is done as well as the situatedness of action within a social milieu. What is then presented here, a becoming ontology, is one in which the social actor is engaged in an unfolding act of transformation. It is this act of transformation, as the results within the articles will argue, that should be at the heart of any theoretical underpinning of project-based learning.

From the position of a becoming or relativist ontology, it should be possible to formulate a series of key principles for researching projects-aspractice. Blomquist et al. (2010, p. 13) presents just such a set of principles suggesting that the research should focus on the following:

- What is done and from there develop an understanding of wider contexts, that is, research is practitioner focused and moves from interior to exterior.

- The practice rather than on models of management such that the reasons for taking actions are made central, for example, how do people actually solve problems.

- The dynamics of communities of practitioners within organisations and the ways these overlap with other organisational communities. 
- The interaction between local and global and exterior and interior factors in order to understand how these factors influence practice.

- The entanglement and intertwining of communities and practices in order to understand the situatedness of practice.

Taking these principles as a starting point, it is understood that "that to develop a sound theoretical basis for project management, the very nature of projects needs to be examined" (Bredillet, 2010, p. 6). This can be undertaken through a synthesis of the reconceptualising of projects that has occurred within organisational studies, with theories of learning and educational development. In doing so it is argued that educators would be better placed to re-imagine project-based learning as an agile pedagogy for 'social learning' (Wenger-Trayner \& Wenger-Trayner, 2015) not as a model for the management of learning.

\section{Case Studies}

This chapter asks if it is possible to enhance real world learning experiences through the use of live projects in Higher Education. It proposes that in order to better understand how real world learning occurs within an HEI setting, our understanding of the nature of live projects, and by inference project-based learning, needs to be reformulated. The chapter proposes a shift from projects as models of management and rethinking of projects as forms of social practice. It suggests that if educators wish to enhance the use of live projects within the curriculum, then it might be helpful to think of projects as a social domain rather than an administrative tool. To do so allows for the shift from the short-term interiority of task-based learning in which teams coalesce around tasks and disperse upon completion as typified by the use of fully or partially simulated live projects within individual modules or units of learning. Towards an approach in which students begin the process of socialisation into the community of practice they will encounter on their transition from education into employment.

The chapter presents three case studies which to varying degrees attempt to address this need to ease students across the boundary between 
employment and education. Case Study 1 outlines a project undertaken by Interior Design students at Derby University who were challenged to design a mobile public art space. Case Study 2 sketches out a project undertaken by postgraduate Culture, Policy and Management students at City University that engaged with small cultural enterprises to provide marketing support, while Case Study 3 saw Journalism students at Sheffield University participate in a live 'Newsday' style event supported by professional data journalists. In each case the use of a live project aims to introduce students to the application of theory to practice, provide for an engagement with industry, structuring activity around the principle of learning by doing. In each case the project sought to generate an encounter with the real world for students that would ease their transition from education to employment.

To what extent the cases presented here achieve these goals can be evaluated against the degree to which the students begin the process of socialisation into their respective communities of practice. This can be characterised further by analysing the occurrence of 'social learning' (Wenger-Trayner \& Wenger-Trayner, 2015) in each of the cases. For Wenger-Trayner and Wenger-Trayner (2015) 'social learning' occurs within communities of practice. It is the process of acquiring membership of a community that has ongoing 'continuity and purpose', infers the adoption of a 'shared identity' and a 'collective intention' towards a sustained contribution to a shared domain of disciplinary knowledge.

Case Study 1 perhaps exemplifies this ethos best with its focus on 'conversations' between industry professionals and students as novice practitioners. The partnership appears to have established behavioural norms and sets out a collective sense of a work ethos. It is assumed, this would have been further enforced by the participation of industry professionals who would have modelled these kinds of behaviours for students. Siting much of the activity for the project off-campus also provided for a deepened real world context. While the public launch of the project frames the project as having a real world output, a live project of this kind requires a real world client with a real business need to achieve the situatedness that brings liveness to a project (Hanney, 2013). This project achieves this goal while also offering a civic context thereby situating professional practice within the context of a public space. This gives the 
project a real sense of value and places the students practice firmly within the context of a creative industries business model. The key element of the project that meets the requirement for social learning is the modelling of practice by industry professionals in partnership with the students. While there is always likely to be an element of simulation in any educationally contrived project, the partnership model offered here must surely offer the most beneficial experience for the students.

The biggest challenge for all of the case studies presented here is the allocation of resources. Setting up live projects can be extremely time consuming and risky (e.g. the author's own experience of a live project, the client for which was declared bankrupt mid project, is an example of the kind of risk that might be encountered). The investment in time for staff, students and industry professionals can be high. Industry partners can be asked to work with inexperienced students to deliver high-quality outputs to clients under tight deadlines. Timelines for real world projects rarely fit within narrow academic scheduling. Projects are often transdisciplinary and may require additional academic and/or practical support to deliver project outputs. Case Study 2 attempts to negotiate some of these challenges by shifting some of the work of setting up the project onto the students. In this case study the students are required to selfselect a client and to manage that relationship themselves. Given the nature of the organisations with which the students engage there are clearly opportunities for students to bring real world value to the projects they undertake for these organisations. The students are required to negotiate with their self-selected clients, identify problems and present solutions. There is certainly a strong sense of the situatedness of the project as a real world learning experience. However, the students are asked to think of themselves as a sub-department within the organisation for whom they are undertaking the project, or to consider themselves as a team of external consultants. In both cases the students conceptualise themselves as exterior to the organisation whose sole role is to function as a client for the project. This is perhaps the most common formulation of a live project, for example, students work as a team to deliver a project for an external client. The main issue with this approach is that the social learning is limited to encounters with the client, intra-team collaboration and academic input. There is little if any modelling by industry professionals (in 
this case marketing professionals), mentoring is undertaken by the academics supporting the project and while students undoubtedly gain confidence and expertise, there is little if any prospect of their socialisation into a community of practice.

Case Study 3 meets these challenges halfway by bringing professionals on campus to work with students to deliver project outputs. This works in this particular context as the students are familiar with the 'Newsday' as a simulated classroom-based activity. The inclusion of practicing journalists into the environment added a liveness to the event that enabled the course team to introduce a new and challenging topic of study. There is a strong emphasis on 'learning by doing' and again we see students working in partnership with industry professionals. Here there is going to be a significant amount of modelling of practice, a sharing of tacit knowledge of social norms, community etiquette and a deepening of disciplinary knowledge through applied learning strategies. The use of peer feedback to further embed ownership of learning is significant here as is the sense that 'social learning' is not always hierarchical. Of course, one of the aspects of a 'Newsday' style of activity is that there is an additional kind of deadline-related liveness present within the activity. This is akin to the kinds of time-constrained challenges offered by hackathons or 48-hour film challenges. Time becomes a key driving factor in the delivery of the project outputs.

The main issue that this final case presents concerns the simulated nature of the project. The activity aims to mimic, mirror or transfer the newsroom experience to the classroom. While there is nothing wrong with simulated experiences as a mode of learning by doing it begs a question as to whether or not the activity is actually project-based learning at all. Perhaps it would be more appropriate to think of this case study as an example of task-based learning. The lack of a real-value output to an external client is key here and while the involvement of industry professionals is indicative of a potential for social learning a live project must surely include some kind of deliverable output for a real client who gains some business value from the interaction (Hanney, 2013). It would seem that Case Studies 2 and 3 present two halves of the equation: Case Study 2 lacks the mentoring of industry professionals, while Case Study 3 lacks the real-value project output for a client. 
Nevertheless, both of these case studies evidence real value for students who gain better understanding of the subject they are studying. In all three case studies there is a clear sense of learning by doing, of mirroring of industry practice, and, to a differing degree, all three include some forms of social learning. However, if the purpose of the projects in each case study is to ease the transition between the education and the world of work it is arguable that there are limitations at play. These may well be in part down to the constraints around resources (time and cost) as well as issue of quality (of the experience and of the project outputs). It is clear from all of the case studies that live projects are challenging to set up and deliver. No doubt this presents difficulties for educators wishing to develop a real world learning approach within their own curriculum. The benefits to the students though are vividly captured by the three case studies. Students develop more advanced skills, acquire disciplinary vocabulary, and foster industry contacts and awareness of professional practice. All of the case studies to one degree or another begin the process of socialising students as novices into their destination community of practice.

\section{Case Study 1}

Acting Locally, Thinking Globally: Design Within Out Walls (Dr Rhiannon Jones, Post-Doctoral Researcher, Digital Material Artistic Research Centre, College of Arts, Humanities and Education, School of Arts, University of Derby, UK)

A cohort of Interior Design students undertook a live project to develop a conceptual idea for a mobile touring art space in partnership with a 'creative industry client'. Entitled S.H.E.D. the brief asked students to design a reconfigurable touring space that would facilitate community dialogue, thereby framing students' understanding of industry-facing relationships and project management through the simulation of a real world business encounters. The S.H.E.D live project encouraged students to explore and develop their own voice and design identity, creating inspiring solutions for spatial environments including residential, commercial and historical spaces. The degree programme 
facilitates learning in dedicated professional design studios and acquiring a range of skills in the design and development of spaces as well as being involved in live projects, where students have collaborative opportunities with local and international partners. The live project aimed to take a project off-the-page, from classroom to workshop-and then straight to market. The brief asked students to investigate possibilities for converting a garden shed into a mobile touring structure to operate as a public art space with multiple configurations (from intimate space to festival stage). It needed to be robust and movable; retain its DIY, upcycled aesthetic; consider the ongoing touring costs and material maintenance; be suitable for both indoor and outdoor use, day and night. Learning outcomes considered client's needs, construction, materials and finishes, services, zoning, furniture, and ergonomics.

Students were encouraged to think as experts and equals. Industry colleagues engaged with the students as knowledgeable co-creatives, not as novices or student learners. Students were equal creative partners and treated as colleagues. Everyone attended meetings, presentations and workshops contributing equally to creative decision-making. Due to the tight deadline for delivery, the project was reliant on the student's active participation and working ethos in order to make this possible. The brief was discussed weekly and tailored sessions nurtured ideas as a group and responded to the students' design processes. Meetings took place offcampus: they were taken out of the classroom to the art studio. Working in a real world setting enhanced the dedication and care given to the brief. Conversations were essential to building a collective, rather than a competitive ethos. Media students documented the project, and this enabled peer-to-peer interdisciplinary learning.

An industry launch served as a means for further situating the student's participation in a real world context which placed the students centre stage at this public event. A panel discussion, with industry feedback on the design, gave students a sense of pride and ownership. Students saw their design concepts realised as a pragmatic artefact. They made professional industry connections and became more civic minded through the design process, which required them to answer questions about how to design dialogic spaces. They developed skills in new areas through participatory engagement with industry professionals rather than just with 
tutors. A community of practice emerged, enabled through a multifaceted framework for learning, where students, in partnership with industry professionals, balanced pressure and responsibility to deliver an industry-ready product. Real world learning was not simulated here; it was actualised, embedded and industry-facilitated through constant open and creative dialogue. The whole degree course is dynamic and co-creative in that it welcomes students' own voices/cultures and values risk-taking and experimentation. It further aims to equip students with all the relevant skills and knowledge ready for the 'real' world upon graduation. Live projects provide exposure to the wide field, that is, interior design, exploring various spatial typologies such as residential interiors, commercial interiors, that is, retail, corporate, set-stage and exhibition design and hospitality, as well as exploring adaptive reuse/regenerative design to name but a few, with a focus on employment opportunities open to an interior design graduate.

This live project challenged preconceptions around applied learning and creative industry partnerships can achieve within an educational context. Students 'shed' preconceived ideas about where pedagogy takes place and increased their personal and professional confidence. They continue to have ongoing involvement in a project that otherwise would not exist without participation in the project. However, live projects of this kind require an investment of time that is difficult to negotiate within the highly scheduled world of academia. Furthermore, the educational context is not ideally placed to deliver to industry deadlines or time scales. There is also a need for industry professionals to devote extended amounts of time to a project of this nature which may conflict with commercial needs.

\section{Case Study 2}

Connecting Theory with Practice in Arts Marketing ( $D r$ Ana Gaio, Programme Director, MA Global Creative Industries, School of Arts and Social Sciences, Department of Sociology, City University, UK)

A group of postgraduate Culture, Policy and Management (CPM) students undertook a live project with a self-selected London-based arts/ 
cultural organisation. The project was undertaken as part of an Audiences and Marketing (module) which sought to re-problematise concepts learned in other (core) Managing Organisations and Culture modules. The module aims to explore the claims made by practitioners and academics that the specificity of arts/cultural marketing derives from the interrelationships between culture, policy and management. It requires students to approach the topic strategically and applies theory to practice. It also enables students to look at the arts marketing paradigm from a Cultural Policy (core module) perspective although links can be found with most other modules. Ultimately, the project reflects and articulates the MA CPM's bias towards the state sponsored cultural sector as well as its cross-disciplinary nature. The brief required students to devise a marketing strategy for their chosen client. Students are supported but ultimately each team is expected to converge around their project to mobilise and manage its mix of marketing knowledge, experience and talent. The organisations selected by the students are normally small cultural organisations (any art/cultural form) which are either known to a student/s or found through networking. Once groups identify their organisations, they negotiate access to it, research it and develop a full marketing strategy for the client organisation. Learning outcomes included application of theory to practice, facilitation of interaction with marketing professionals, evaluation of the specificity of arts/cultural marketing to encourage the formation of communities of learning.

Students are given freedom to decide how they organise themselves and their work. No specific direction is given in terms of project management. It is assumed that as students will have taken a core management module in a previous semester, they already have a grounding in organisational strategy and management. Gathering information involves engaging with relevant organisation staff, identifying problems, attending events, audience observation and demographic research. Students will typically evaluate relevant organisational documentation and review its existing marketing strategies (although in small organisations, especially, marketing activity is often reactive or tactical). Students know that the marketing strategy is the group's and not the organisation's but understand the need to explain their choices in their final assessment submission. Developing the marketing strategy will normally entail dialogue 
with the organisation in order to generate cogent, realistic and supported claims. Whilst a debrief between students and organisation is not required, this often happens as students test their findings with the organisation in the project's final stages.

The self-selected client organisation is not involved in the assessment and the project is clearly framed as a student-led educational activity that sits within a course module. Through immersion, situated learning, students gain experience of the day-to-day reality of arts marketing practice in cultural organisations and combine 'theoretical knowing' with 'application to practice'. Their engagement with the staff at the selected organisation introduces the students to the community's ways, culture and jargon thereby contributing to the beginning of the student's socialisation into a community of practice, a 'peripheral participation' of sorts. The students also benefit from the development of intra-group social capital through meaningful participation. By the end of the experience students display a comprehensive and in-depth knowledge and understanding of marketing and its key concepts, their relevance or application (or not) to arts marketing. They talk about and use marketing language meaningfully and comfortably and display a newfound confidence. Many students add this project to their CVs which evidences the significance that participation in the project has for them individually. The applied nature (partly, at least) of CPM as a field of studies inherently calls for engagement with the sector and the arts marketing project effects the MA CPM's aims to develop the student as an independent and critical individual; produce competent professionals ready to enter the cultural sector and to engage with the sector. Preparing students for employment and enhancing their employability are key to this agenda - the arts marketing project is instrumental in connecting students, especially those interested in a marketing career, with the sector and its arts marketing community, day-to-day practice and realities.

While this live project aims to replicate the kind of learning that occurs in everyday work and the membership of a community of practice there are constraints around the project's ability to achieve these aims. Students are encouraged to work closely with the client organisation, and this often includes close collaboration. However, the experience of student groups is highly variable and dependant of a wide range of factors. The 
ideal is for students to work in partnership with the selected organisation as if they were a department within the organisation (e.g. marketing team) or as a team of external consultants. Negotiating relations with the selected organisation is complex and success often depends on factors such as group cohesion, work ethic and application of disciplinary knowledge. Furthermore, the commitment of the client organisation is also subject to variability of conditions since the project doesn't always have a real world benefit for the selected organisation and this can impact positively or negatively on the experience.

\section{Case Study 3}

Data Hounds-Learning to Research, Analyse and Visualise (Dr Lada T. Price, Course Leader, MA Journalism, Department of Media Arts and Communications, Sheffield Hallam University, UK)

The live project began when we invited two experts from the Press Association (PA) to assist us in designing and running workshops for beginner data journalists on the BA and MA Journalism courses. Both are professionally accredited by the National Council for the Training of Journalists (NCTJ) and aims to prepare students for work in digital newsrooms. Students have to excel at traditional newswriting as well as being able to work with new digital formats and show they can work with data accurately and efficiently. Most news organisations now expect their employees to have these skills and this project aimed to provide Journalism students with sufficient insights and techniques to help them in their future employment. The aim of the project was to teach future journalists how to gather, process and present quantitative data. The possession of data skills opens up new possibilities for students to tell a compelling story in traditional and digital formats and is applicable in all stages of the journalistic process. We organised interactive workshops with the experts from the PA creating learning experiences that simulate the real world of journalism practice. The majority of our 34 undergraduate and postgraduate Journalism students described their skills and experience of working with data prior to the workshops as 'none' or 'basic'. 
The workshops were structured in a way that ensures students' active involvement and contribution. The plan was based entirely on daily reallife news practice at the PA in order to 'transfer' the newsroom into the classroom. Apart from a brief explanation of what 'data journalism' is and what it entails in daily journalism practice, the rest of the workshops were very hands-on and focused on a 'learning by doing' experience. Organised in small teams the students worked together with the journalists. They were very eager to get input and tips from practicing data journalists and apply this to their learning. The participants were particularly interested in how journalists put together stories at the PA step by step and mirror this process in their own work. While several students experienced difficulties during an exercise on obtaining and structuring data accurately, guidance from the experts helped to successfully complete the task. Students were most engaged with the content during the final part of the workshop, which mimicked live 'breaking news' event. This was seen an opportunity to put everything they had learned in practice. There was a 'buzz' of activity and conversation with the PA journalists (as editors) as students organised themselves in a pattern they were already familiar with due to regular intensive 'newsdays' held throughout their courses of study.

The most valuable aspect of the workshop was working together with journalists and receiving one-to-one guidance during tasks that were perceived as complex and unfamiliar. During the workshops, students received expert feedback but were also assessing and generating their own feedback. We learned that students who had very little knowledge or experience of data journalism can be encouraged and inspired through practical and fun tasks that they perceived as 'very useful' and 'valuable' for their future journalism practice. The feedback showed that being taught and working alongside experienced professionals in data journalism was praised by all participants as it allowed them to actively participate in a real-life newsroom experience. The journalists noted that they enjoyed sharing their professional tips with the students and treated all participants as equals. The project participants developed skills in sourcing and structuring of data in order to present it in an optimal manner for analysis; how to go about extracting stories from data using the analytical techniques most commonly employed by the PA; outlining and communicating analytical findings in a way that others can use through 
storyboarding and briefing; learning key principles of data visualisation and the use of graphics to illustrate information.

While the planning and delivery of the project went smoothly, we found that on the days of the workshops several students who had signed up did not attend. It's possible that they were anxious or nervous about the prospect of working with highly experienced professionals. Previous research suggests that journalists sometimes openly admit that they chose a career in journalism to escape numeracy. Working with data is a challenge for young and aspiring journalists who sometimes lack basic mathematic skills and they could feel they were not up to the task. If we were to do this again, we would invite the journalists to speak to students in a very informal Q\&A session before they came to conduct the workshops. This of course would be difficult as our 'teachers' were working journalists who cannot take time off work regularly to do this. Our project concluded that introducing modules on working with data in the journalism curriculum, where students become accustomed to basic and more advanced skills, can be significantly enhanced by inviting data journalists to share their everyday practical experience and work alongside learners.

\section{Conclusion}

It is argued above that a 'becoming mode' (Hanney, 2018) of projectbased learning $(\mathrm{PjBL})$ foregrounds the learnability of the experience of undertaking project work. This ontological shift away from models of management towards a reconceptualisation of projects as a practice places the pedagogic imperative at the heart of project working. Importantly, it provides a philosophical underpinning for thinking about projects as a fundamentally social practice. The fetishisation of 'industry practices' is subsumed to the needs of the educational context, while assessment focuses less on 'connoisseur' evaluation of project outputs in favour of reflection on experience and lessons learned. In its ideal form students will undertake live projects situated in a real world context with a real client, who has a real business need. Furthermore, there is an expectation that the output of a project should at least have the potential for real business value for the client. 
As has been shown above there are variations on this formulation that move between the ideal and innumerable other approaches that are more or less simulated. The client may be more or less real, be external/internal to the educational context, be imagined, be self-selected, or otherwise provided. What is argued here is that the role of the client is less important than the coaching role of industry professionals since the client really only serves to provide a real world context. What is crucial to the experience and what is missing from most live projects to one degree or another is the integration of mentoring, modelling and coaching from industry professionals. It is this factor that is most likely to drive student's engagement, motivation and participation. It is the beginning of their initiation into a community of practice that is of most pedagogic value, not their interactions with a proposed fictional/real client. That is not to say that these interactions are not of value. But let's be real about this, in the real world, novices don't get to lead client negotiations as this is often a mission critical to the business concerned.

If the transition between the educational context and employment is an important factor for students, then their awareness of the kinds of social behaviours that would be expected of them by their chosen community of practice must be paramount. Novices are socialised through participation in the community and over time gain tacit knowledge of the social norms, etiquette and deepen disciplinary knowledge through applied learning strategies. Members provide support for each other, form relationships based around mutual learning, engage in reputation building and crucially interact regularly and learn together. Importantly, members of the community are practitioners who share a repertoire of tools, techniques, strategies that are commonly recognised as a domain of practical activity. One of the ways that the community bonds is around shared repertoire of stories, cases and mythologies which inform their practice, stories the students will only encounter through interaction with other members of a community of practice.

All three of the case studies presented in this chapter offer a means for students to begin this transition and start their initiation into a chosen community of practice. In each case study, educators have developed a methodology for live projects that to one degree or another support that process. There are clearly challenges though. Foremost among these are 
the constraints around the kinds of resources required to support the administrative burden that comes with live projects. The inflexibility of timetables and the academic lifecycle also poses problems. Engagement with potential clients, industry professionals and the kind of relationship building this requires also poses a challenge for educators. Nonetheless, it is important to recognise that if real world learning is to be adopted as a primary pedagogic discourse then the use of live projects with highquality mentoring/modelling/coaching from industry professionals is the gold standard for project-based learning.

\section{References}

Blomquist, T., Hällgren, M., Nilsson, A., \& Söderholm, A. (2010). Project-aspractice: In search of project management research that matters. Project Management Journal, 41(1), 5-16. https://doi.org/10.1002/pmj

Bourdieu, P. (1984). Distinction: A social critique of the judgement of taste. London: Routledge \& Kegan Paul.

Bourdieu, P. (1988). Vive la Crise!: For heterodoxy in social science. Theory and Society, 17(5), 773-787.

Bourdieu, P. (1990). The logic of practice. Cambridge: Polity.

Bredillet, C. (2010). Blowing hot and cold on project management. Project Management Journal, 41(3), 4-20. https://doi.org/10.1002/pmj.20179

Cicmil, S., Hodgson, D., Lindgren, M., \& Packendorff, J. (2009). Project management behind the facade. Ephermera theory \& politics in organization, 9(2), 78-92.

Floricel, S., Bonneau, C., Aubry, M., \& Sergi, V. (2014). Extending project management research: Insights from social theories. International Journal of Project Management, 32(7), 1091-1107. https://doi.org/10.1016/j. ijproman.2014.02.008

Gauthier, J.-B., \& Ika, L. A. (2012). Foundations of Project Management research: An explicit and six-facet ontological framework. Project Management Journal, 43(5), 5-23. https://doi.org/10.1002/pmj.21288

Giddens, A. (1984). The constitution of society: Introduction of the theory of structuration. Berkeley: University of California Press. 
Hanney, R. (2013). Towards a situated media practice: Reflections on the implementation of project-led problem-based learning. Journal of Media Practice, 14(1), 43-59. https://doi.org/10.1386/jmpr.14.1.43_1

Hanney, R. (2018). Doing, being, becoming: A historical appraisal of the modalities of project-based learning. Teaching in Higher Education, 23(6), 769-783. https://doi.org/10.1080/13562517.2017.1421628

Hodgson, D., \& Cicmil, S. (2008). The other side of projects: The case for critical project studies. International Journal of Managing Projects in Business, 1(1), 142-152. https://doi.org/10.1108/17538370810846487

Hodgson, D. E., \& Cicmil, S. (2006). Are projects real? The PMBOK and the legitimisation of project management knowledge. In D. E. Hodgson \& S. Cicmil (Eds.), Making project critical (pp. 29-50). Basingstoke: Palgrave Macmillan.

Lewis, B. (2013). What is a project? Towards a new ontology for projects and project management. Paper presented at the Critical Management Studies Conference, University of Bristol.

Linehan, C., \& Kavanagh, D. (2006). From project ontologies to communities of virtue. In D. E. Hodgson \& S. Cicmil (Eds.), Making projects critical (pp. 51-67). Basingstoke: Palgrave Macmillan.

Lundin, R. A., \& Söderholm, A. (1995). A theory of the temporary organization. Scandinavian Journal of Management, 11(4), 437-455. https://doi. org/10.1016/0956-5221(95)00036-U

Morris, P. W. G. (1994). The management of projects. London: Thomas Telford.

Nicholas, J. M. (2004). Project management for business and engineering: Principles and practice (2nd ed.). London: Elsevier.

Packendorff, J. (1995). Inquiring into the temporary organization: New directions for project management research. Scandinavian Journal of Management, 11(4), 319-333. https://doi.org/10.1016/0956-5221(95)00018-Q

Sahlin-Andersson, K., \& Söderholm, A. (2002). Beyond project management: New perspectives on the temporary-permanent dilemma. Abingdon: Marston Book Services.

Seo, M.-G., \& Creed, W. E. D. (2002). Institutional contradictions, praxis, and institutional change: A dialectical perspective. The Academy of Management Review, 2, 222.

Shenhar, A., \& Dvir, D. (2007). Reinventing project management: The diamond approach to successful growth and innovation. Boston, MA: Harvard Business School Press. 
Svejvig, P., \& Andersen, P. (2015). Rethinking project management: A structured literature review with a critical look at the brave new world. International Journal of Project Management, 33(2), 278-290.

Wenger, E. (1998). Communities of practice: Learning, meaning, and identity. Cambridge: Cambridge University Press.

Wenger-Trayner, E., \& Wenger-Trayner, B. (2015). Introduction to communities of practice: A brief overview of the concept and its uses. Retrieved from https://wenger-trayner.com/introduction-to-communities-of-practice/

Winter, M., Smith, C., Cooke-Davies, T., \& Cicmil, S. (2006). The importance of 'process' in rethinking project management: The story of a UK governmentfunded research network. International Journal of Project Management, 24(8), 650-662.

Open Access This chapter is licensed under the terms of the Creative Commons Attribution 4.0 International License (http://creativecommons.org/licenses/ by/4.0/), which permits use, sharing, adaptation, distribution and reproduction in any medium or format, as long as you give appropriate credit to the original author(s) and the source, provide a link to the Creative Commons licence and indicate if changes were made.

The images or other third party material in this chapter are included in the chapter's Creative Commons licence, unless indicated otherwise in a credit line to the material. If material is not included in the chapter's Creative Commons licence and your intended use is not permitted by statutory regulation or exceeds the permitted use, you will need to obtain permission directly from the copyright holder.

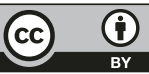

